\title{
Thermal comfort study of naturally ventilated office
}

\author{
Marta Laska, ${ }^{1, *}$ \\ ${ }^{1}$ Wroclaw University of Science and Technology, Faculty of Environmental Engineering, \\ Wybrz. Wyspianskiego 27, 50-370 Wroclaw, Poland
}

\begin{abstract}
It is well known that people spend about $90 \%$ of their lifetime in buildings where the indoor environment strongly influences their health and productivity. Therefore it is crucial to maintain proper internal conditions, and thus ensure comfort environment for building users. Due to the nature and complexity the thermal comfort is difficult to describe with physical parameters. However there is a number of available methods to assess the indoor conditions and define the comfort level - from simplified methods based on the measurement of basic parameters to complex approach - with the use of computational fluid dynamics engineering tools. The paper presents the outcome of the thermal comfort study for a naturally ventilated office located in Wroclaw (Poland). The chosen physical parameters has been registered in long- and short-term perspective, and later used for defining the boundary conditions and CFD model validation.
\end{abstract}

\section{Introduction}

People spend most of their time indoors. The building is a shelter from external conditions, so the interior has to be safe and comfortable for its users. The building environment strongly influences not only human comfort, but also the life, activity, health and productivity. Therefore the main concern of the engineers and researchers is to identify crucial factors and parameters influencing thermal comfort and maintain them on expected level. The combination of these physical and individual variables defines levels of thermal comfort and thus the user's satisfaction from the thermal environment. There is a certain number of methods to estimate the thermal comfort in rooms - from simplified, based on the variability of one parameter to complex approaches - based on the relationship between environmental and personal factors or implementation of numerical tools. These methods are still evaluating and are under improvement as they have limitations depending on outdoor conditions, building types, specific requirements of the users or the installations the building is equipped.

The indices and methods for estimating thermal comfort are evaluating from the $1930 \mathrm{~s}$ [1]. Today the most common methods are based on Fanger's theory and operative temperature approach and are described in the European Standards 7730 and $15251[2,3]$

*Corresponding author: marta.laska@pwr.edu.pl 
respectively. The simple method based on relationship between the air temperature and relative humidity but under constant clothing insulation value (clo) of 0,6 and sedentary activity was developed by Rholes [4] His extended model dedicated for wider range of clo was described by Burati et all. in [5]. The adaptive predicted mean vote (aPMV), Human Thermal Model (HTM), adaptive comfort algorithm (ACA) in comparison with classic comfort approach represented by Fanger's theory are described in paper [6] as methods more flexible than classic adaptive approach. The example of the application of most complex approach in comfort study based on CFD modelling is described in [7]. The literature presents also examples of comfort study for mechanically ventilated enclosures $[8,9,10]$ as well as naturally ventilated buildings [11-13].

The paper focuses on estimating comfort conditions in naturally ventilated office located in Wroclaw (Poland). The applied method is based on an approach described in standard EN 15251 [3]. It assumes that in naturally ventilated buildings working in freerunning mode human body easier adapts to the surrounding due to his/her thermoregulation system. It is applicable for free-running buildings as well as periodically heated, cooled and running under a mixing mode, and is based on a theoretical value - an operative temperature. This method combines two parameters that need to be measured, namely indoor air temperature and mean radiant temperature. The literature [14] indicates that in well-insulated buildings, where the influence of exterior is small, the difference between air, mean radiant and thus operative temperature is negligible. To check this theory the relationship between these parameters is investigated and the statistical methods are applied. The investigated office was also subjected to a long-term assessment and CFD modelling. Therefore the last part of the article presents the outcome of these analysis.

The European Standards [2, 3] define also other methods for steady- and not-steadystate conditions based on temperature drifts, temperature steps, cycling temperatures or temperature ramps. However these are not under the interest of this paper.

\section{Comfort study}

\subsection{Investigated room}

The study was conducted in the naturally ventilated office room located on the first floor of the two-storey building. The main geometry data: room area equals $21,3 \mathrm{~m}^{2}$, room clear height is $3 \mathrm{~m}$, clear length of the external wall is $5,1 \mathrm{~m}$, two windows of $112 \times 150 \mathrm{~cm}$. The room geometry is presented on the Fig. 1. The external wall and windows are directed towards south-west. The comfort conditions during heating season in the office are provided by classic radiator-based water system. In summer office works in a free-running mode. The European Standards [2,3] defines the range of comfort operative temperatures depending on the class of the building. The investigated room can be classified as category II (B) - dedicated for renovated buildings or cat. III (C) - for existing buildings. In winter time the operative temperature range for cat. II (B) is defined as $20-24^{\circ} \mathrm{C}$ for cat. III (C) is defined as $19-25^{\circ} \mathrm{C}$. The limit values for summertime are described by proper equations described in [3]. 


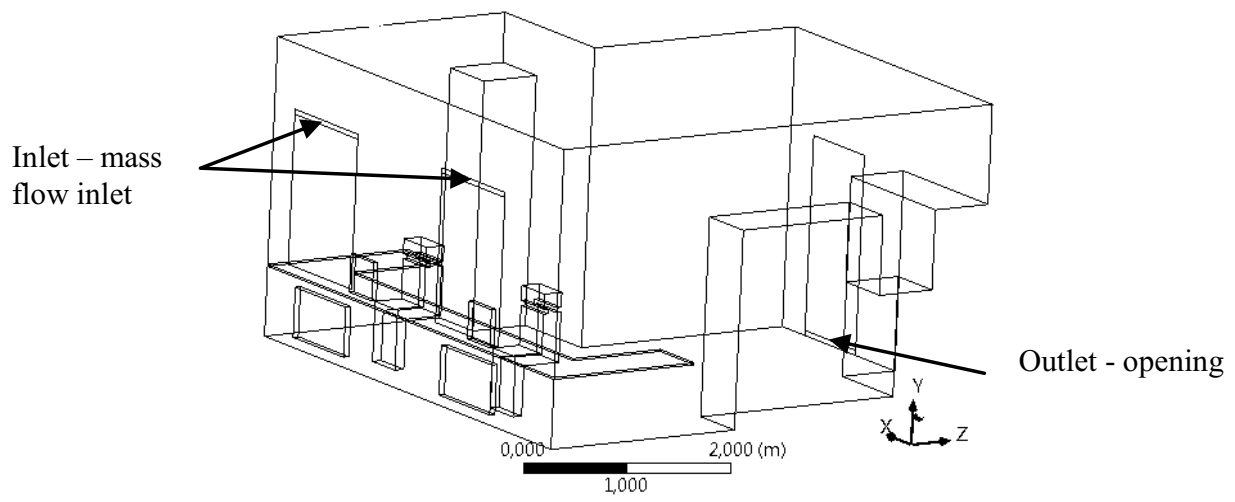

Fig. 1. Geometry of the investigated office with the description of main boundary conditions.

\subsection{Indoor air temperature measurements}

Measurement of air temperature in the room was performed continuously during the period from February to December 2014 in the 10-minute interval. The following data loggers have been used: Volcraft DL-141 TH with the accuracy of $\pm 1{ }^{\circ} \mathrm{C}$ for the temperature range from $-10^{\circ} \mathrm{C}$ to $+40^{\circ} \mathrm{C}$ and Rotronic $\mathrm{CL} 11$ with the accuracy of $\pm 0,3^{\circ} \mathrm{C}$ for the temperature range from $0^{\circ} \mathrm{C}$ to $+50^{\circ} \mathrm{C}$. The variation of recorded parameter is presented on the Fig. 2. The surface temperatures were measured by the set of thermocouples connected to the logger.

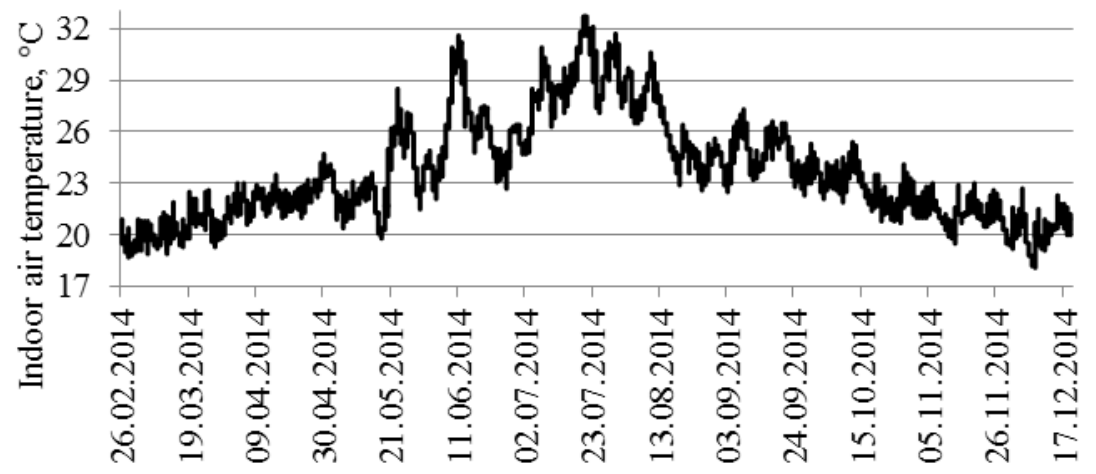

Fig. 2. The internal temperature variation during measurement period: 26.02 .2014 to 19.12 .2014 .

The recording period started at 11:05 a.m. on $26^{\text {th }}$ of February 2014. The last measurement took place at 14:15 p.m. on $19^{\text {th }}$ of December 2014.

The highest temporary internal temperature of $32,7^{\circ} \mathrm{C}$ was measured during the night time on $21^{\text {st }}$ of July when the office daily-average was $32,14^{\circ} \mathrm{C}$. The lowest temporary internal temperature was recorded during morning hours (between 6 and 8 a.m.) on Monday the $8^{\text {th }}$ of December and reached $18,1^{\circ} \mathrm{C}$. The highest temperature at this day occurred between 6 and 7 p.m. when the mean external temperature was $+1^{\circ} \mathrm{C}$ and reached $20,7^{\circ} \mathrm{C}$.

\subsection{Operative temperature}

The air temperature and its variation are the main environmental parameters in comfort level estimations, however the most common simple indicator is an operative temperature. 
It is a pure theoretical value, thus it cannot be obtained directly due to an empirical study. The operative temperature can be calculated from [14]:

$$
T_{o}=H \cdot T_{a}+(1-H) \cdot T_{r}
$$

where $T_{a}$ is air temperature; $T_{r}$ is mean radiant temperature; $H$ is a value described by the relationship between convective heat transfer coefficient and linear radiation transfer coefficient. The $H$ parameter is difficult to estimate and differs between researchers, therefore CIBSE (UK Charter Institution of Building Services Engineers) proposed to correlate the $T_{o p}$ with the air velocity [14]. For natural convection it can be assumed to be $0,1 \mathrm{~m} / \mathrm{s}$ thus the simplified equation describing operative temperature can be written as [14]:

$$
T_{o}=0,5 T_{a}+0,5 T_{r}
$$

To estimate the value of operative temperature and its variation for investigated office the inner surface temperatures of surrounding surfaces was recorded over the period of time: from $26^{\text {th }}$ of September to $4^{\text {th }}$ of December. The mean values of measured parameters and calculation outcomes are presented on the Fig. 3. The gap in data collection from $1^{\text {st }}$ to $13^{\text {th }}$ of November was caused by fluctuating problems with electrical network in the building and thus recording equipment.

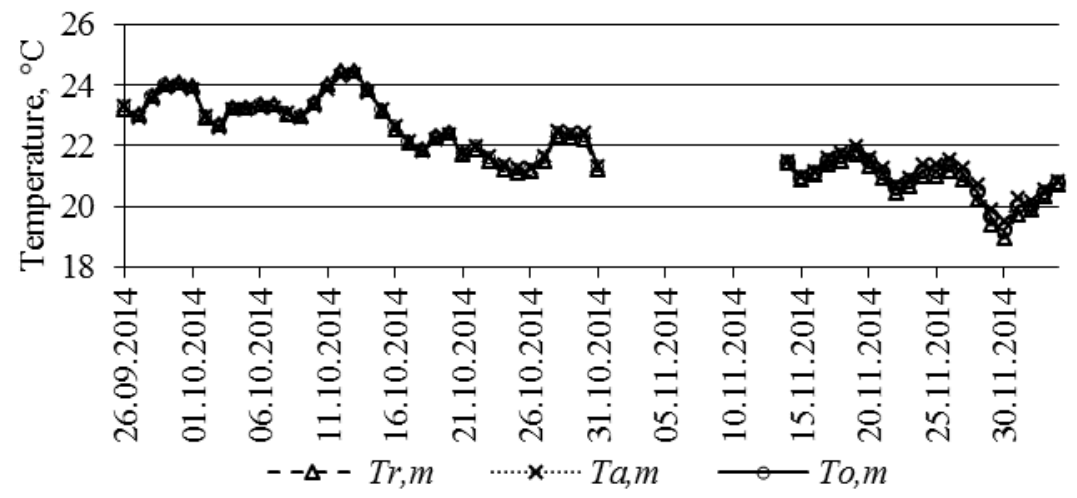

Fig. 3. The variation of mean values of radiant temperature $\left(T_{r, m}\right)$, room air temperature $\left(T_{a, m}\right)$ and operative temperature $\left(T_{o, m}\right)$.

Data presented on the Fig. 3 clearly states that during the considered period, the discrepancies between mean indoor air and radiation temperature is negligible, and thus the variation of the operative temperature is close correlated with the room temperature.

\subsection{Statistical relationship between air and radiant temperature}

The statistical analysis is an important part of each scientific research. Therefore this paragraph presents the results of the statistical analysis of the relationship between indoor air temperature and the temperatures of surrounding surfaces, and their influence on the office air temperature. Persons correlation coefficient $(r)$ defines strength of relationship between independent variables and $\mathrm{p}$-value defines statistical significance of the relation for particular set of data points. The value of the coefficient can vary between -1 and 1 , and thus the correlation is assumed to be strong if $|r|$ is bigger than 0,7 or medium to week if $|r|$ is in the range of $\langle 0 ; 0,7\rangle$.

The calculated Pearson correlation coefficients for the relationship between the indoor temperature and the temperature of inner surfaces of external wall, windows and flat roof 
were calculated and amount respectively $0.973 ; 0.855$ and 0.989 what proves strong relation between analyzed data.

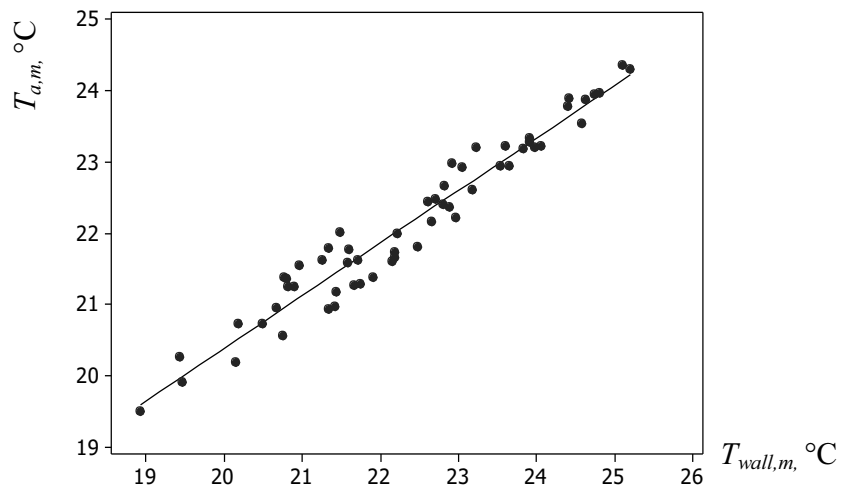

Fig. 4. Function 1 - describes the relationship between mean (daily-average) indoor temperature $T_{a, m}$ and mean temperature of the inner surface of external wall $T_{\text {wall, } m \text {. }}$.

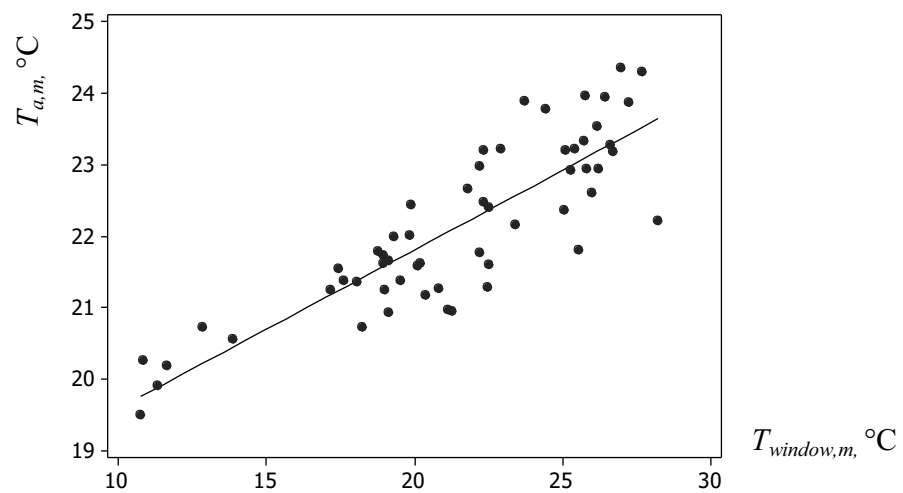

Fig. 5. Function 2 - describes the relationship between mean (daily-average) indoor temperature $T_{a, m}$ and mean temperature of the inner surface of windows $T_{\text {window, } m}$.

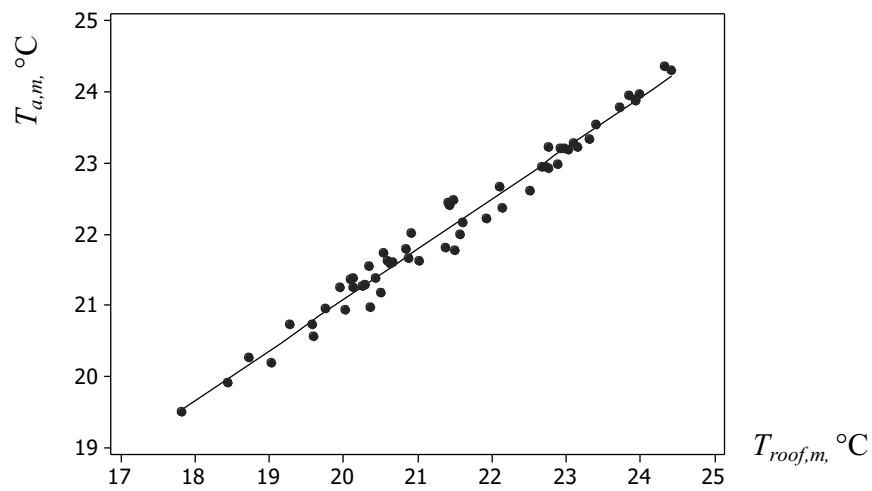

Fig. 6. Function 3 - describes the relationship between mean (daily-average) indoor temperature $T_{a, m}$ and mean temperature of the inner surface of flat roof $T_{\text {roof }, m}$.

To define functions describing the mathematical model of the relationship between air temperature and the temperatures of surrounding surfaces (and thus the room radiant temperature), the regression analysis has been applied. 
The outcome of the analysis in graphic forms are presented on the Fig. 4., Fig. 5., Fig. 6. The mathematical equations describing these relationships are presented in Table 1. The residuals analysis which is out of scope for this paper.

To check the statistical significance of the correlation between the analyzed parameters, the significance level of 0,05 was assumed as for engineering applications. In all three cases the calculated $\mathrm{P}$-value was lower than 0,05 . Therefore, the null hypothesis $\mathrm{H}_{0}$ that the data are independent is rejected and the alternative hypothesis $\mathrm{H}_{\mathrm{a}}$ of a statistical significance is adopted. Present statistical significance (P-value) and strong variables correlations $(r)$ are also confirmed by high value of determination coefficient $R^{2}$ for each function (Table 1), what is typically called "practical" significance and can be read as portion of real data variation explained or determined by the particular math model.

Table 1. The determination coefficients $R^{2}$ for the functions describing the relationship between the daily-average indoor temperature and the temperatures of internal surfaces of the building envelope.

\begin{tabular}{|l|c|c|}
\hline $\begin{array}{c}\text { Function } \\
\text { no. }\end{array}$ & Mathematical model & $\begin{array}{c}\text { Determination } \\
\text { coefficient } \\
\mathbf{R}^{\mathbf{2}}\end{array}$ \\
\hline Function 1 & $\mathrm{y}=5.612+0.7386 \mathrm{x}$ & $94.7 \%$ \\
\hline Function 2 & $\mathrm{y}=17.35+0.2228 \mathrm{x}$ & $73.0 \%$ \\
\hline Function 3 & $\mathrm{y}=6.859+0.7108 \mathrm{x}$ & $97.7 \%$ \\
\hline
\end{tabular}

Presented in Table 1 models describe very well the relationship between discussed parameters therefore at this stage of the investigation there is no need for expanding the models for bigger number of freedom of the subsequent points or introducing new variables increasing the models complexity.

The proposed equations can be applied at the later stage of the research as a boundary conditions when considering CFD simulations of the office under dynamic state. However it is not the scope of this paper.

\subsection{Long-term comfort assessment}

The other approach of estimating comfort conditions assumes long-term measurements as described in [3]. The method classifies the enclosure to one of four categories of indoor conditions and is based on the daily average room temperature during the heating period.

Table 2. The percentage of time for a given temperature range (defined for a particular class of the building) in monthly cycle (on 24-hours basis).

\begin{tabular}{|c|c|c|c|c|}
\hline $\begin{array}{c}\text { Building category/ } \\
\text { Month }\end{array}$ & I & II & III & IV \\
\hline March & $19.5 \%$ & $45.4 \%$ & $34.1 \%$ & $1.0 \%$ \\
\hline April & $91.5 \%$ & $6.8 \%$ & $1.7 \%$ & $0.0 \%$ \\
\hline October & $63.5 \%$ & $29.4 \%$ & $6.6 \%$ & $0.5 \%$ \\
\hline November & $67.4 \%$ & $23.9 \%$ & $8.7 \%$ & $0.0 \%$ \\
\hline December (19 days) & $19.0 \%$ & $49.7 \%$ & $21.7 \%$ & $9.6 \%$ \\
\hline
\end{tabular}


Following [3] the room initially was classified as category III (with lower standards of comfort, as described in section 2.1), but the analysis of the temperature during office "working hours" indicated that the room can be classified as cat. II (with the percentage of people dissatisfied lower than $10 \%[2])$.

Additional analysis of the percentage of time in a given month on a 24-hours basis when the office meets the class requirements has been performed. The time of occurrence of the temperature range corresponding to different classes of buildings is presented in Table 2.

\subsection{CFD simulations}

In the final stage of the investigation, the office was simulated in ANSYS (CFD tool) under steady - state conditions. The created geometry (Fig. 1) was divided on a certain number of control volumes. The defined boundary conditions are presented in Fig. 1. The other elements are defined as surfaces with constant temperature (taken from the measurements) or as adiabatic walls. For the simulation SST k- $\omega$ turbulence model was applied $[8,10]$. The simulation outcomes are presented on Fig. 7 and Fig. 8.

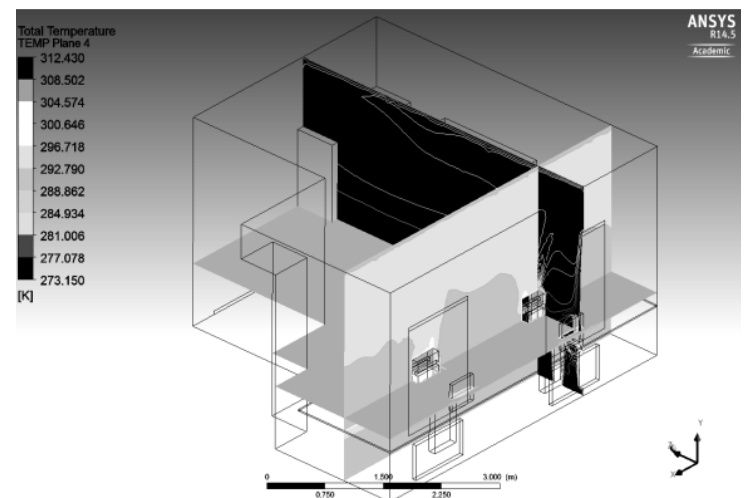

Fig. 7. The temperature distribution profile in a three control planes.

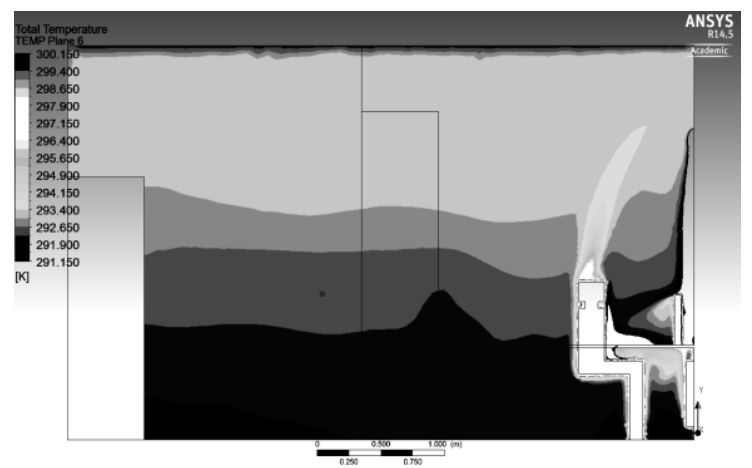

Fig. 8. The temperature distribution profile in a vertical plane. The temperature range: $18^{\circ} \mathrm{C}$ to $27^{\circ} \mathrm{C}$.

The resulting maps of temperature in simulated office are in line with expectations. Measured room temperature for given boundary conditions was $20,5^{\circ} \mathrm{C}$. According to the model, this level of temperature is achieved at about 1,7 m, which well corresponds with the sensor position and its readings within the tested room. 


\section{Conclusion}

The paper presented chosen methods of assessing comfort conditions that can be applied for naturally ventilated rooms. The measurements of indoor temperature and surrounding surfaces were undertaken to calculate operative temperature, to perform long-term estimation of comfort, to define boundary conditions of the CFD office model and to compare with the simulation outcomes. The statistical analysis, as an important element of the scientific research, was applied. It was based on the regression method to establish and validate the relationship between measured parameters.

The paper indicated that there is a number of well described in the literature methods of assessing indoor comfort conditions. From the simple and common to the advanced and complex approaches, in short and long perspective. Each method has its own limitations and applicability. However, as thermal comfort is an important aspect in terms of building operation, satisfaction and productivity of building users, therefore the comfort investigation, even by application of simple methods, should be an important element of engineering practice.

\section{References}

1. M. Taleghani, M. Tenpierik, S. Kurvers, A. Dobbelsteen, Renew Sust Energ Rev, 26, 201-215 (2013)

2. EN ISO 7730 Analytical determination and interpretation of thermal comfort using calculation of the PMV and PPD indices and local thermal

3. EN 15251 Indoor environmental input parameters for design and assessment of energy performance of buildings- addressing indoor air quality, thermal environment, lighting and acoustics

4. F.H. Rohles, Hum Factors, 13, 553-60 (1971)

5. C. Buratti, P. Ricardi, M. Vergoni, Appl Energ, 104, 117-127 (2013)

6. R. Holopainen, et all., Build Environ, 71, 60-70 (2014)

7. P. Aryal, T. Leephakpreed, Energy Procedia, 79, 183 - 188 (2015)

8. A.Stamou, I. Katsiris, Build Environ, 41, 1171-1181 (2006)

9. M.Kavgic, D. Mumovic, Z. Stevanovic, A.Young, Energ Buildings, 40, 1334-1343 (2008)

10. S. Hussain, P.H. Oosthuizen, Appl Therm Eng, 40, 358-372 (2012)

11. J. Song, X. Men, Procedia Engineering, 121, 1475 - 1481 ( 2015 )

12. T. van Hooff, B. Blocken, Y. Tominaga, Build Environ, 114, 148-165 (2017)

13. K.W.D. Cheong, et all., Build Environ, 38, 63-73 (2003)

14. F. Nicol, M. Humphreys, S. Roaf, Adaptive thermal Comfort. Principles and Practice (Routledge, London, 2012)

15. M.A. Baharun, M. Surat, N.M. Tawil, A.I. Che-Ani, E3S Web of Conferences 3, 01008 (2014)

16. P.O. Fanger, Komfort cieplny (Arkady 1974) 